\title{
A importância do portfólio crítico-reflexivo na graduação de medicina: Uma experiência acadêmica
}

The importance of the critical-reflexive portfolio in medicine graduation: An academic experience La importancia del portafolio crítico-reflexivo en la graduación de medicina: Una experiencia académica

Recebido: 05/07/2021 | Revisado: 10/07/2021 | Aceito: 12/07/2021 | Publicado: 23/07/2021

Mariana do Prado Borges

ORCID: https://orcid.org/0000-0002-7032-8920 Instituto Tocantinense Presidente Antônio Carlos, Brasil E-mail: marianapb_96@ hotmail.com

Augusto Wickert Schaedler

ORCID: https://orcid.org/0000-0003-0705-0361 Instituto Tocantinense Presidente Antônio Carlos, Brasil E-mail: augustows10@ hotmail.com

Felipe Batista Rezende

ORCID: https://orcid.org/0000-0002-0207-5650 Instituto Tocantinense Presidente Antônio Carlos, Brasil E-mail: felipeb.rezende@hotmail.com

Jordana Lucio Garcia

ORCID: https://orcid.org/0000-0002-4290-3369 Instituto Tocantinense Presidente Antônio Carlos, Brasil E-mail: garcia.jordana04@gmail.com

Ana Lidia de Campos Lico

ORCID: https://orcid.org/0000-0002-0272-4315 Instituto Tocantinense Presidente Antônio Carlos, Brasil E-mail: analidiacamposlico@gmail.com

Guilherme Wickert Schaedler

ORCID: https://orcid.org/0000-0002-7352-0176 Instituto Tocantinense Presidente Antônio Carlos, Brasil E-mail: guilhermews15@gmail.com

Marcella Crystina Ramos Queiroz ORCID: https://orcid.org/0000-0002-7112-5631 Instituto Tocantinense Presidente Antônio Carlos, Brasil E-mail: marcellaramos20@gmail.com

Aline Alves de Oliveira

ORCID: https://orcid.org/0000-0002-8254-2174 Instituto Tocantinense Presidente Antônio Carlos, Brasil E-mail: aline.oliveiraa1998@gmail.com

Thales Arthur Cotolengo De Pina ORCID: https://orcid.org/0000-0002-0740-955X Instituto Tocantinense Presidente Antônio Carlos, Brasil E-mail: thalmidim@outlook.com

Lorena Dias Monteiro

ORCID: https://orcid.org/0000-0002-2246-3490 Instituto Tocantinense Presidente Antônio Carlos, Brasil E-mail: lorenamonteiro3@hotmail.com

\section{Resumo}

Objetivo: Este relato de experiência tem como propósito relatar a importância do portfólio crítico-reflexivo no desenvolvimento de valores, conhecimentos, habilidades e atitudes médicas durante a graduação de medicina. Metodologia: Trata-se de experiências vivenciadas no período de 01 de agosto de 2017 a 30 de junho de 2019 por acadêmicos de medicina da Faculdade ITPAC Palmas- TO durante as aulas práticas do módulo de Integração Ensino Serviço Comunidade. Desde o primeiro período os alunos são inseridos nos Centros de Saúde da Comunidade do Município de Palmas no intuito de construir nexos teóricos e práticos relacionados ao Sistema Único de Saúde. A cada encontro semanal há produção de uma lauda do portfólio com uma narrativa sobre a experiência vivenciada e sua análise crítica-reflexiva. No fim do período os acadêmicos entregam os portfólios e recebem uma devolutiva do tutor ressaltando aspectos sobre conhecimentos, habilidades e atitudes. Resultado e Discussão: A dinâmica proposta pelo portfólio crítico-reflexivo permite aos acadêmicos o reconhecimento das diversas situações de saúde em sua singularidade, por meio do pensamento e imaginação. As trocas de experiências relatadas proporcionam aos 
estudantes o entendimento e julgamento das situações, possibilitando a criação de percepções, pensamentos, valores e aperfeiçoamento de habilidades e atitudes médicas diante do paciente e equipe de trabalho, corroborando para uma graduação humanizada. Conclusão: A construção da graduação médica com o uso de metodologias ativas de ensinoaprendizagem, como os portfólios crítico-reflexivos, contribui para a formação de valores para atuação no campo da saúde, tais como reflexão crítica, empatia e criatividade.

Palavras-chave: Educação médica; Aprendizagem; Metodologias ativas; Ensino.

\begin{abstract}
Objective: This experience report aims to report the importance of the critical-reflective portfolio in the development of values, knowledge, skills and medical attitudes during medical graduation. Methodology: These are experiences lived from August 1, 2017 to June 30, 2019 by medical students from Faculdade ITPAC Palmas-TO during practical classes of the Integration Teaching Service Community module. From the first period, students are inserted in the Community Health Centers of the Municipality of Palmas in order to build theoretical and practical links related to the Unified Health System. At each weekly meeting, a portfolio page is produced with a narrative about the experience experienced and its critical-reflective analysis. At the end of the period, the students deliver the portfolios and receive a feedback from the tutor highlighting aspects of knowledge, skills and attitudes. Results and Discussion: The dynamics proposed by the critical-reflective portfolio allows academics to recognize the different health situations in their uniqueness, through thought and imagination. The exchanges of experiences reported provide students with understanding and judgment of situations, enabling the creation of perceptions, thoughts, values and improvement of medical skills and attitudes towards the patient and work team, supporting a humanized graduation. Conclusion: The construction of medical graduation using active teaching-learning methodologies, such as critical-reflective portfolios, contributes to the formation of values for action in the health field, such as critical reflection, empathy and creativity.

Keywords: Education medical; Learning; Active methodologies; Teaching.
\end{abstract}

\begin{abstract}
Resumen
Objetivo: Este informe de experiencia tiene como objetivo reportar la importancia del portafolio crítico-reflexivo en el desarrollo de valores, conocimientos, habilidades y actitudes médicas durante la graduación médica. Metodología: Son experiencias vividas desde el 1 de agosto de 2017 al 30 de junio de 2019 por estudiantes de Medicina de la Faculdade ITPAC Palmas-TO durante las clases prácticas del módulo Comunidad de Integración de Servicios Docentes. Desde el primer período, los estudiantes se insertan en los Centros Comunitarios de Salud del Municipio de Palmas con el fin de construir vínculos teóricos y prácticos relacionados con el Sistema Único de Salud. En cada encuentro semanal se produce una página de portafolio con una narrativa sobre la experiencia vivida. y su análisis crítico-reflexivo. Al final del período, los estudiantes entregan los portafolios y reciben una retroalimentación del tutor destacando aspectos de conocimientos, habilidades y actitudes. Resultados y Discusión: La dinámica propuesta por el portafolio crítico-reflexivo permite a los académicos reconocer las diferentes situaciones de salud en su singularidad, a través del pensamiento y la imaginación. Los intercambios de experiencias reportados brindan a los estudiantes la comprensión y juicio de situaciones, posibilitando la creación de percepciones, pensamientos, valores y mejora de las habilidades y actitudes médicas hacia el paciente y el equipo de trabajo, apoyando una graduación humanizada. Conclusión: La construcción de la titulación médica mediante metodologías activas de enseñanza-aprendizaje, como los portafolios crítico-reflexivos, contribuye a la formación de valores para la acción en el campo de la salud, como la reflexión crítica, la empatía y la creatividad.
\end{abstract}

Palabras clave: Educación médica; Aprendizaje; Metodologías activas; Enseñanza.

\title{
1. Introdução
}

No contexto das atuais diretrizes nacionais e internacionais da educação universitária acredita-se na necessidade de implementação de novos métodos de se pensar e praticar o processo de ensino-aprendizagem que aprimore o desenvolvimento de competências e forme profissionais com perfil crítico-reflexivo com capacidade para trabalhar em equipes (Brasil, 2014; Cotta, Costa \& Mendonça, 2015; Franco et al., 2020).

O desafio acerca das metodologias inovadoras de ensino-aprendizagem é desenvolver a mudança de foco do processo de educação visando o fomento do sentido de autonomia, criatividade e responsabilidade, possibilitando que o aluno aprenda a buscar soluções e a resolver problemas profissionais (Cotta, Mendonça \& Costa, 2011; Sandra, 2016).

Nesta concepção, um dos instrumentos estratégicos utilizados na construção do ensino-aprendizado pelas metodologias ativas é o portfólio. O portfólio pode ser definido como um conjunto de trabalhos no qual o estudante retrata sua história de vida, seus progressos e realizações, destacando sua participação na seleção e julgamento dos conteúdos procurados, o que promove uma reflexão e o desenvolvimento da capacidade crítica (Klenowski, 2007; McGuire \& Lay, 2019). 
O termo portfólio é amplo e apresenta várias possibilidades, tendo como principal fator de aprendizagem a construção pelo próprio aluno. De forma progressiva, ao longo do semestre letivo, o acadêmico vai organizando suas produções, as quais evidenciam o seu processo de construção do saber (Villas Boas, 2004; Gutiérrez, Lara, Alpuche, Trejo \& Sánchez, 2019). Deste modo, o portfólio se qualifica como uma ferramenta de avaliação formativa, por promover uma aprendizagem pautada no feedback professor-aluno, por desenvolver competências e habilidades respeitando o ensino em diferentes contextos, focando em resultados centrados no processo, e não na forma pontual e quantitativa utilizada nas avaliações tradicionais (Cotta, Mendonça \& Costa, 2011).

Com base nestas considerações preliminares há o seguinte questionamento: Portfólios crítico-reflexivos desenvolvidos por acadêmicos de medicina da ITPAC Palmas- TO no módulo de Integração Ensino Serviço Comunidade contribuem para a formação médica? Assim, este relato de experiência tem como propósito relatar a importância do portfólio crítico-reflexivo no desenvolvimento de valores, conhecimentos, habilidades e atitudes médicas durante a graduação de medicina.

\section{Metodologia}

O processo metódico tem natureza qualitativa e trata-se de uma análise realizada por meio de um relato reflexivo de experiência, estruturado a partir do uso da ferramenta do Portfólio Crítico-Reflexivo desenvolvidos por discentes de medicina da Faculdade ITPAC Palmas- TO no módulo de Integração Ensino - Serviço - Comunidade (IESC) durante o período de 01 de agosto de 2017 a 30 de junho de 2019 (Estrela, 2018; Ludke \& Andre, 2013).

Configurando o eixo de atividade integradora de formação, o módulo de IESC durante $o 1^{\circ}$ ao $5^{\circ}$ período da grade curricular da faculdade insere os alunos uma vez por semana nos Centros de Saúde da Comunidade (CSC) do município de Palmas - TO para construírem nexos teóricos e práticos relacionados ao Sistema Único de Saúde (SUS). Os acadêmicos são distribuídos em pequenos grupos entre os 34 CSC de Palmas - TO no qual cada um possui um docente para supervisionar e orientar as atividades programadas. Através desse momento, a formação acadêmica transfigura-se à prática, sob dimensões dos três níveis de atenção à saúde.

A cada encontro semanal há produção de uma lauda do portfólio com uma narrativa sobre a experiência vivenciada e sua análise crítica-reflexiva. A construção desta lauda é orientada pela metodologia de problematização, tendo como referência o método do Arco de Maguerez, e visou ao desenvolvimento das cinco competências descritas por Fallows e Steven: habilidade de comunicação em geral; gestão da informação (busca, seleção, análise e avaliação da informação procedente de diversas fontes); habilidades para a utilização de novas tecnologias; trabalho em equipe, ética, reconhecimento da diversidade, exercício da alteridade, resiliência, compaixão, solidariedade, paciência e escuta qualificada; competências pessoais, como gestão do tempo, responsabilidade e planejamento (Cotta, Mendonça \& Costa, 2011). 
Figura 1: Método do arco de Maguerez.

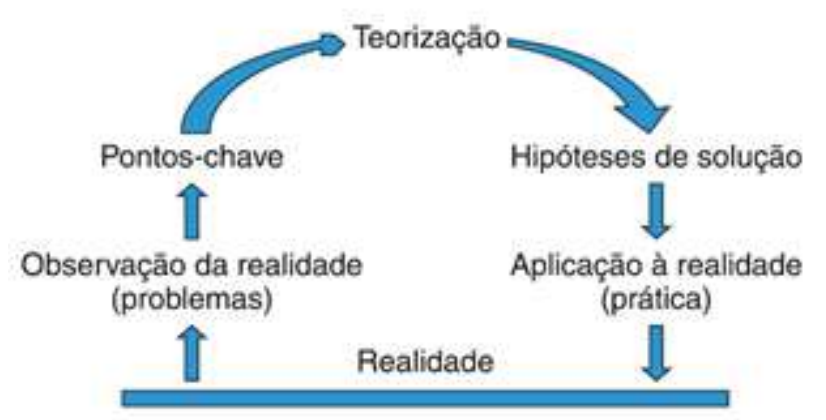

Fonte: Adaptado de Bordenave e Pereira (1998).

No fim de cada período os alunos entregaram o portfólio construído e receberam uma devolutiva do tutor/docente ressaltando aspectos sobre conhecimentos, habilidades e atitudes.

\section{Resultados e Discussão}

Durante a presente experiência os acadêmicos abordaram temas como: aspectos estruturais, conceituação em saúde, políticas públicas de saúde, territorialização, saúde mental, saúde da mulher, criança e adolescente.

No primeiro período a construção do portfólio era simplificada, sem estímulo pela busca de referencial teórico e de utilização da criatividade como charges e outros componentes. A partir do segundo período, momento no qual já se estabeleceu uma relação de convívio com o tutor e com a dinâmica do CSC, a produção desta ferramenta de estudo passou a ser valorizada e empenhado um tempo maior para sua elaboração. A quebra de paradigmas e preconceitos com o Sistema Único de Saúde e a vivência com a sociedade foi fundamental para uma melhoria na construção do portfólio crítico-reflexivo e para a formação acadêmica. Há estudos que mostram que os estudantes em contato com a comunidade relataram a influência na humanização de suas futuras práticas médica e profissional, na medida em que puderam entender a visão do paciente em sua complexidade (Dantas et al., 2017).

A experiência de trabalhar com esta ferramenta da metodologia ativa é surpreendente, pois em primeiro momento houve uma negação e questionamentos da necessidade de elaborar a escrita e criar problematização das vivências da prática. Porém, com o processo de construção dos portfólios e com o amadurecimento dos alunos para a importância de tal evidenciou uma evolução do senso crítico acadêmico, à medida que a convivência aumentava e os conteúdos eram trabalhados no módulo foi adquirido a capacidade de relacionar esses materiais e discutir criticamente com a realidade vivenciada. Outros estudos demonstram a relevância do uso de tais ferramentas da metodologia ativa para estimular a autonomia da aprendizagem a partir de problemas e situações reais, enfatizando o protagonismo do acadêmico no seu processo de aprendizagem (Morán, 2015).

O desenvolvimento desta importante ferramenta estimulou uma melhor compreensão e conhecimento sobre o SUS, com o uso de problematização foi possível ter uma avaliação crítica aos diferentes interesses que permeiam a saúde com uma visão ampliada e pautada na importância de seus determinantes sociais no processo saúde-doença. Observou-se também que houve uma mudança ao longo dos períodos sobre a concepção e paradigmas estabelecidos acerca do SUS e das políticas de saúde. 
Tabela 1: Visão acadêmica sobre a Política Nacional de Saúde antes e depois da construção do portfólio crítico-reflexivo.

\begin{tabular}{c|c}
\hline \multicolumn{2}{c}{ SUS } \\
\hline Antes & Depois \\
\hline \multicolumn{2}{c}{ Construção do Portfólio } \\
\hline Doença & Saúde \\
\hline Cura/medicamento & Promoção/prevenção \\
\hline Ruim/descontentamento & Bom/contentamento \\
\hline Para pobres/focalizado & Para todos/universal \\
\hline Individual & Coletivo/cidadania \\
\hline Teórico & Prática/realidade \\
\hline
\end{tabular}

Fonte: Adaptado de Cotta et al. (2011).

No decorrer destes dois anos, produzindo 4 portfólios críticos-reflexivos, foi compreendido como buscar informações, utilizá-las da melhor forma com capacidade de demonstrá-las e aplicá-las em momentos oportunos de forma autônoma e responsável. Com a prática e motivação houve o desenvolvimento de competências as quais são essenciais para um saber fazer, saber conviver, saber utilizar estrategicamente o conhecimento e saber ser (Polydoro et al., 2015; Brook \& Upitis, 2015; Cotta, Costa \& Mendonça, 2015).

Em nível da formação na graduação, as competências a serem estimuladas são aquelas que deverão estar centradas: na compreensão de conhecimentos adquiridos, na elaboração de críticas e argumentos, na comunicação clara e explícita, no trabalho em equipe, no compromisso ético, na aplicação dos conhecimentos à prática profissional, no entendimento da cultura, crenças e costumes dos povos em que se esteja trabalhando, na compreensão da diversidade, entre outros (Mitre et al, 2008; Cotta, Mendonça \& Costa, 2011; Lizarraga, 2010). Assim, com o uso de metodologias ativas, como por exemplo o portfólio, houve uma melhoria no desenvolvimento dessas competências a partir do momento que o aluno se torna a pessoa ativa em busca de seus conhecimentos.

A experiência de construção do portfólio resultou no desenvolvimento de competências necessárias ao futuro profissional de saúde: cognitiva (reflexão), psicológica (consciência do seu papel profissional) e atitudinal (mudança de postura na formação e prática do aluno baseado nas Diretrizes Curriculares Nacionais e na consolidação do SUS) (Pintrich, 2000; Blanco, 2009; Moniz, 2015; Medeiros, Dantas, Tres, Ramos \& Assunção, 2020). 
Figura 2: Sistematização de competências cognitivas e metacognitivas.

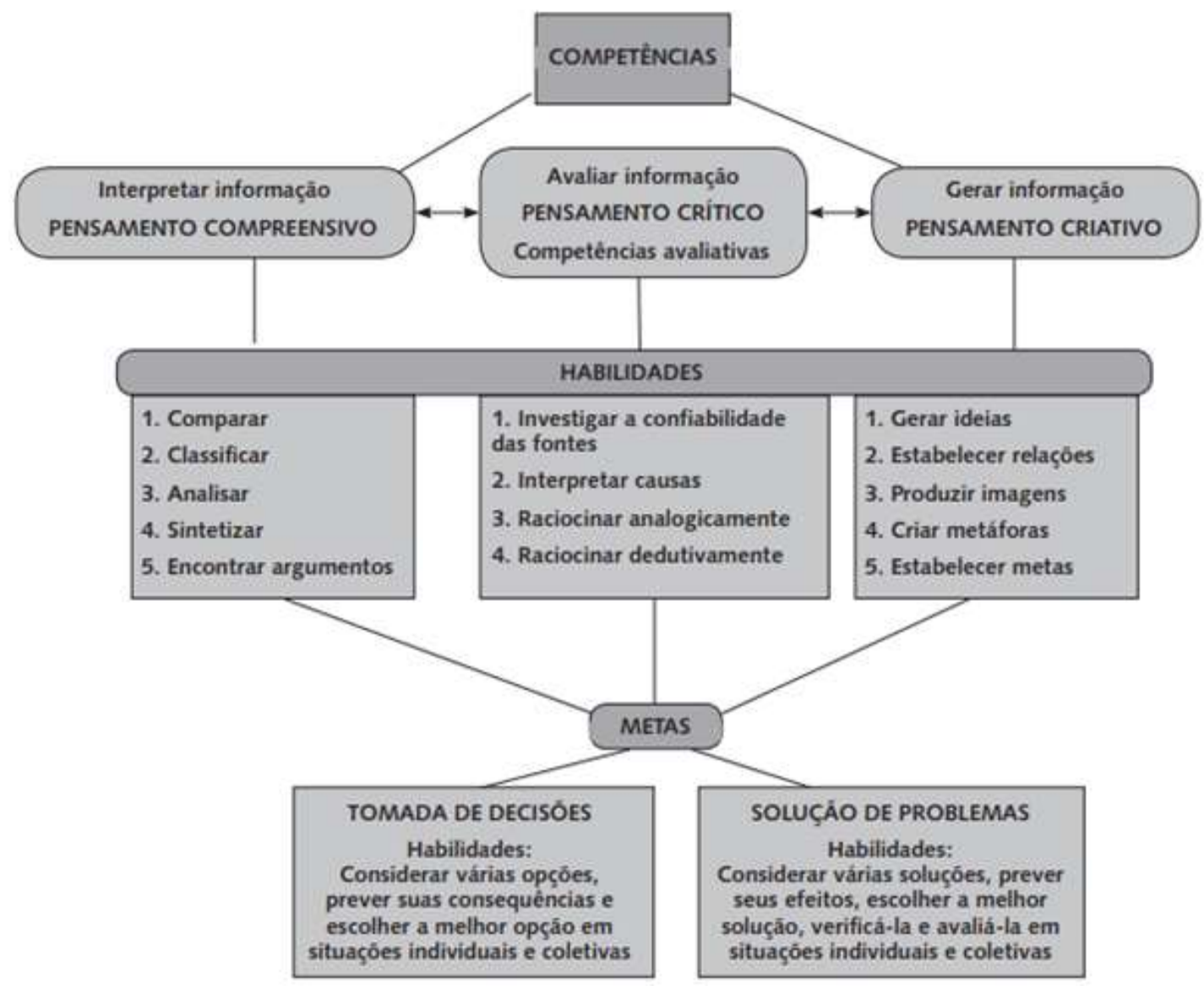

Fonte: Cotta et al. (2015).

Algumas limitações existiram durante a experiência destes quatro períodos construindo portfólios críticos-reflexivos. Uma delas é a disposição de tempo ideal e adequado para a elaboração das laudas como também uma dificuldade de correção e compreensão das ideias descritas por parte dos tutores/docentes responsáveis.

Neste contexto, ressalto a importância de um tutor/docente dedicado nas atividades práticas e na devolutiva de feedbacks professor-aluno para uma contribuição benéfica na construção das competências necessárias para um bom profissional (Buckley et al, 2009). Destaca-se a necessidade de capacitação do docente para o trabalho com portfólio; alguns estudos salientam ser primordial que os educadores sejam formados, construindo seus próprios portfólios - aprender fazendo antes de programarem essa estratégia com seus alunos (Cotta, Costa \& Mendonça, 2015).

\section{Conclusão}

O presente relato de experiência mencionou a importância do portfólio crítico-reflexivo no desenvolvimento de valores, conhecimentos, habilidades e atitudes médicas durante a graduação de medicina. Em um período de dois anos a construção de portfólios das aulas práticas do módulo de IESC da Faculdade ITPAC Palmas- TO contribuiu para o aprendizado e desenvolvimento de competências que tornam os acadêmicos mais ativos, investigadores críticos, abertos ao diálogo e ao novo.

Diante do que foi discutido percebe-se que o portfólio é retratado como um mecanismo de avaliação, sendo este de forma gradual e contínua. No entanto, como o portfólio permite a avaliação contínua, ele se tornou um dos instrumentos mais 
justos e eficazes no processo de avaliação, mas para que esse objetivo seja alcançado junto com o processo de ensino e aprendizagem é fundamental que seja compreendido como ferramenta no compartilhamento de experiências, quando sua função não é compreendida, e ele se torna apenas um arquivo de materiais perdendo sua função e eficácia.

Acredita-se ainda que esse instrumento permite que os alunos criem seu próprio conhecimento e deixe de ser apenas um mero receptor de informações, tornando-se ativo no processo de ensino-aprendizagem. O acadêmico é incentivado a buscar referencial teórico que pode contribuir na sua reflexão diante das situações em que é exposto.

Por meio de problematização e reprodução disto nas laudas desenvolvidas foi compreendido que tais aprendizados e competências adquiridas em cada dia de prática e elaboração do portfólio me prepara não somente para o mundo do trabalho, mas para a vida.

Abordar essa temática é fundamental para a compreensão da importância e a aprimoração do uso do portfólio na graduação médica. A maioria de estudos que retratam sobre esse tema não são recentes e dessa forma não acompanham as atualizações e mudanças ocorridas nos métodos de aprendizagem nos últimos anos.

\section{Referências}

Blanco, A. (2009). Desarrollo y evaluación de competencias en educación superior. Narcea.

Bordenave, J. D. \& Pereira, A. M. (1998). Estratégias de ensino-aprendizagem. (19a ed.), Vozes.

Brasil. Ministério da Educação. (2014). Resolução $n^{o}$ 3, de 20 de junho de 2014. Institui diretrizes curriculares nacionais do curso de graduação em Medicina e dá outras providências. Conselho Nacional de Educação. Câmara de Educação Superior. Diário Oficial da União. Sec. 1, p. 8-11.

Brook,J \& Upitis, R. (2015). Can an online tool support contemporary independent music teaching and learning? Music Education Research, 17(1), 34-47. https://doi.org/10.1080/14613808.2014.969217

Buckley, S., Coleman, J., Davison, I., Khan, K. S., Zamora, J., Malick, S., Morley, D., Pollard, D., Ashcroft, T., Popovic, C., \& Sayers, J. (2009). The educational effects of portfolios on undergraduate student learning: a Best Evidence Medical Education (BEME) systematic review. BEME Guide No. 11. Medical teacher, 31(4), 282-298. https://doi.org/10.1080/01421590902889897

Cotta, R. M. M., Costa, G. D. \& Demendonça, E. T. (2015). Portfólios crítico-reflexivos: Uma proposta pedagógica centrada nas competências cognitivas e metacognitivas. Interface: Communication, Health, Education, 19(54), 573-588. https://doi.org/10.1590/1807-57622014.0399

Cotta, R. M., de Mendonça, E. T., \& da Costa, G. D. (2011). Portfólios reflexivos: construindo competências para o trabalho no Sistema Único de Saúde [Learning portfolios as a tool for reflection: building competencies for work in the Unified Health System]. Revista panamericana de salud publica = Pan American journal of public health, 30(5), 415-421. https://doi.org/10.1590/s1020-49892011001100003

Estrela, C. (2018). Metodologia Científica: Ciência, Ensino, Pesquisa. Editora Artes Médicas.

Franco, R., Ament Giuliani Franco, C., de Carvalho Filho, M. A., Severo, M., \& Amelia Ferreira, M. (2020). Use of portfolios in teaching communication skills and professionalism for Portuguese-speaking medical students. International journal of medical education, 11 , 37-46. https://doi.org/10.5116/ijme.5e2a.fa68

Gutiérrez, G.M., Lara, Y.G., Alpuche, A.H., Trejo, A.M. \& Sánchez, M. (2019). Avaliação de competências em residentes de pneumologia pediátrica: utilização do portfólio eletrônico. Neumol Cir Torax, 78 (1), aprox. 5. https://www.medigraphic.com/pdfs/neumo/nt-2019/nt191a.pdf

Klenowski, V. (2007). Desarrollo de portafolios para el aprendizaje y la evaluación. (3a ed.), Narcea.

Lizarraga, M. L. S. A. (2010). Competencias cognitivas en educación superior. Narcea SA Ediciones.

Ludke, M. \& Andre, M. E. D. A. (2013). Pesquisas em educação: uma abordagem qualitativa. E.P.U.

McGuire, L. E., \& Lay, K. A. (2019). Reflective Pedagogy for Social Work Education: Integrating Classroom and Field for Competency-Based Education. Journal of Social Work Education, 1-14. https://doi.org/10.1080/10437797.2019.1661898

Medeiros, M., Dantas, A. S., Tres, G. S., Ramos, A. S. M., \& Assunção, M. V. D. de. (2020). Aprendizagem autorregulada com o uso de portfólio: análises sobre percepções discentes. Research, Society and Development, 9(8), e311985483. https://doi.org/10.33448/rsd-v9i8.5483

Mitre, S. M., Siqueira-Batista, R., Girardi-de-Mendonça, J., Morais-Pinto, N., Meirelles, C., Pinto-Porto, C., Moreira, T. \& Hoffmann, L. (2008). Metodologias ativas de ensino-aprendizagem na formação profissional em saúde: debates atuais. Ciencia \& Saude Coletiva, 13(2), 2133-2144. https://doi.org/10.1590/S1413-81232008000900018

Moniz, T., Arntfield, S., Miller, K., Lingard, L., Watling, C. \& Regehr, G. (2015). Considerações no uso da escrita reflexiva para avaliação do aluno: questões de confiabilidade e validade. Med Educ., 49 (9), 901-8. 
Research, Society and Development, v. 10, n. 9, e16410917922, 2021

(CC BY 4.0) | ISSN 2525-3409 | DOI: http://dx.doi.org/10.33448/rsd-v10i9.17922

Morán, J. (2015). Mudando a educação com metodologias ativas. Coleção mídias contemporâneas. Convergências midiáticas, educação e cidadania: aproximações jovens, 2(1), 15-33.

Pintrich, P. R. (2000). The role of goal orientation in self-regulated learning. In: Boekaerts, M., Pintrich, P. R., Zeidner, M. (eds.) Handbook of self-regulation. (p. 452-502). Academic Press.

Polydoro, S., Pelissoni, A., do Carmo, M., Emilio, E., Dantas, M., \& Rosário, P. (2015). Promoção da autorregulação da aprendizagem na universidade: percepção do impacto de uma disciplina eletiva. Revista de Educação PUC-Campinas, 20(3), 201-213. https://doi.org/10.24220/2318-0870v20n3a2877

Swardt, M., Jenkins, L. S., Von Pressentin, K. B. \& Mash R. (2019). Implementing and evaluating an e-portfolio for postgraduate family medicine training in the Western Cape, South Africa. BMC Med Educ., 19:251. https://doi.org/10.1186/s12909-019-1692-x

Villas Boas, B. M. F. (2005). O portfólio no curso de pedagogia: ampliando o diálogo entre professor e aluno. Educ. Soc., 26(90), 291-306. https://doi.org/10.1590/S0101-73302005000100013 